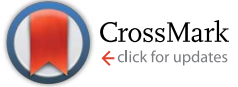

Cite this: RSC Adv., 2017, 7, 1266

Received 15th November 2016 Accepted 29th November 2016

DOI: 10.1039/c6ra26824b

www.rsc.org/advances

\section{Beyond pristine MOFs: carbon dioxide capture by metal-organic frameworks (MOFs)-derived porous carbon materials $\uparrow$}

\author{
Hye Ryeon Kim, ${ }^{a}$ Tae-Ung Yoon, ${ }^{c}$ Seung-Ik Kim, ${ }^{c}$ Jihyun An, ${ }^{* b}$ Youn-Sang Bae*c \\ and Chang Yeon Lee*ad
}

Porous carbon materials were synthesized by simple pyrolysis of various zinc-containing MOFs. These materials exhibited superior $\mathrm{CO}_{2}$ capacities compared to those of the pristine MOFs. Moreover, the porous carbon materials, in contrast to their parent MOFs, showed an excellent $\mathrm{CO}_{2}$ separation ability under humid conditions.
Continuous carbon dioxide $\left(\mathrm{CO}_{2}\right)$ emission from anthropogenic sources causes severe environmental issues such as global warming. The largest $\mathrm{CO}_{2}$-emitting industrial sources are coalfired power plants, in which post-combustion capture is often utilized to remove $\mathrm{CO}_{2}$ from exhaust gas generated from combustion of fossil fuels. Flue gas from power plants is composed of carbon dioxide ( 15-16\%), water vapor $(\sim 5-7 \%)$ and nitrogen $(\sim 70-75 \%)$ at $\sim 1$ bar. $^{1}$ In order to separate and capture $\mathrm{CO}_{2}$ from power plant flue gas emissions, monoethanol amine (MEA)-based aqueous solution is conventionally employed. However, this wet-process requires a high-energy cost to regenerate absorbents because of not only an inherent high heat capacity of water in MEA solution but also chemisorption of $\mathrm{CO}_{2}$ on MEA. Approximately $30 \%$ of energy produced from the power plants is usually wasted to regenerate the aqueous MEA solution. Moreover, volatility of MEA solution at high temperature and its corrosive character limit a wide use of MEA as an adsorbent for large-scale $\mathrm{CO}_{2}$ capture. Porous solid materials, which have lower heat capacity, have been emerging as a potential adsorbent for $\mathrm{CO}_{2}$ capture applications. Materials including zeolites, ${ }^{2}$ carbon materials, ${ }^{3}$ porous organic polymers (POPs), ${ }^{4}$ amine-grafted silicas ${ }^{5,6}$ and so on have been investigated so far.

Among the various porous solids, metal-organic frameworks (MOFs), which are assembled by a coordination bond between

\footnotetext{
${ }^{a}$ Energy and Chemical Engineering, Incheon National University, 119, Academy-ro, Yeonsu-gu, Incheon, 22012, Republic of Korea. E-mail: cylee@inu.ac.kr ${ }^{b}$ Department of Chemistry Education, Seoul National University, 1 Gwanak-ro, Gwanak-gu, Seoul, 08826, Republic of Korea.E-mail: jihyunan@snu.ac.kr

'Department of Chemical and Biomolecular Engineering, Yonsei University, 50 Yonseiro, Seodaemun-gu, Seoul, 03722, Republic of Korea. E-mail: mowbae@yonsei.ac.kr ${ }^{d}$ Innovation Center for Chemical Engineering, Incheon National University, 119, Academy-ro, Yeonsu-gu, Incheon, 22012, Republic of Korea

$\dagger$ Electronic supplementary information (ESI) available. See DOI: $10.1039 / \mathrm{c} 6 \mathrm{ra} 26824 \mathrm{~b}$
}

a rigid organic ligand and diverse metal ions or metal clusters, have emerged as an outstanding adsorbent for $\mathrm{CO}_{2}$ capture because of their enormous surface area and finely tunable surface functionality. The work from Matzger and coworkers has demonstrated MOFs' excellent promising potential as $\mathrm{CO}_{2}$ adsorbent, showing that $\left[\mathrm{Mg}_{2}\right.$ (DOBDC) $]$ (DOBDC $=2,5$-dioxido1,4-benzenedicarboxylate) exhibited a remarkable $\mathrm{CO}_{2}$ uptake capacity (27.5 wt\%) at $298 \mathrm{~K}$ and 1 bar. $^{7}$ However, most MOFs show instability toward moisture unfortunately, and it is one of the greatest challenges for establishing $\mathrm{CO}_{2}$ capture from the flue gas containing water vapor. Particularly, MOF-5 and MOF177, composed of oxo-zinc secondary building unit and carboxylate linker, are known for their extreme instability upon exposure to moisture. ${ }^{8}$ In fact, MOF-5 showed a significant decrease of dynamic $\mathrm{CO}_{2}$ adsorption capacity under humid condition $(\mathrm{RH}=65 \%)$ during three consecutive cycles. ${ }^{9}$

Porous carbon materials and metal or metal oxide-carbon (M@C or MO@C) composites which are derived from MOFs have been used widely as platforms for green energy applications such as fuel cells, Li-ion batteries, supercapacitors and solar cells. ${ }^{10}$ In general, simple pyrolysis of pristine MOF precursors affords these materials, and MOF-derived porous carbon materials are moisture stable due to the inherent hydrophobic property of porous carbon. While numerous examples exist for electrochemical applications with these materials, to the best our knowledge, there are relatively few examples were reported for capturing $\mathrm{CO}_{2}$ with MOF-derived porous carbon materials, ${ }^{11-16}$ and most of the works are limited to ZIF-8 (ZIF: zeolitic imidazolate frameworks) which is constructed from imidazolates and zinc(II) ions. Besides, $\mathrm{CO}_{2}$ adsorption study of these materials under humid conditions has not been reported yet.

Herein we report a simple method for preparing porous carbon materials derived from zinc-containing MOFs (MOF-5, MOF-177, and bioMOF-100) and their $\mathrm{CO}_{2}$ uptake properties. In 


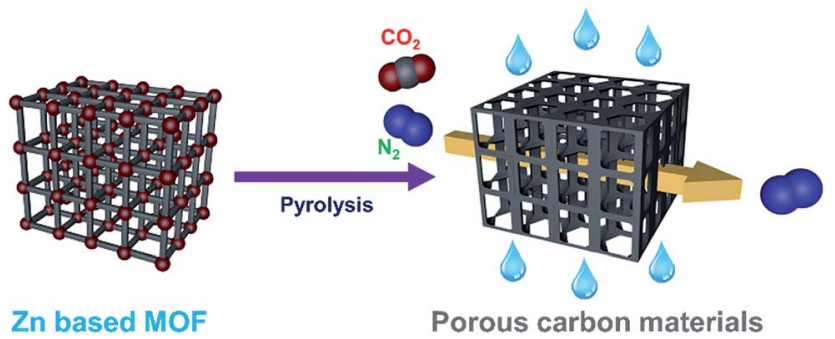

Scheme 1 Schematic illustration of the preparation of porous carbon materials and their selective adsorption of $\mathrm{CO}_{2}$.

addition, dynamic breakthrough experiments for these materials under humid conditions are also represented. We believe that these three MOFs can be suitable precursors for porous carbon materials because they have high surface areas over $3000 \mathrm{~m}^{2} \mathrm{~g}^{-1}$ and thermally removable zinc elements. Furthermore, bioMOF100 contains nitrogens in adeninate ligands, thus $\mathrm{CO}_{2}$ capture performance of nitrogen-doped porous carbon material can be tested as well in this work (Scheme 1).

MOF-5, MOF-177, and bioMOF-100 were synthesized by reported methods. ${ }^{17,18}$ In order to obtain porous carbon materials, zinc-based MOFs were pyrolyzed at $1000{ }^{\circ} \mathrm{C}$ for $6 \mathrm{~h}$ under $\mathrm{Ar}$ atmosphere. During the pyrolysis step, low boiling zinc metal (b.p. $907^{\circ} \mathrm{C}$ ) was completely removed and metal-free carbon materials were afforded consequently. Hereafter resultant porous carbons were denoted as M5-1000, M177-1000, and B100-1000, respectively.

The phase structures of porous carbons were studied via powder X-ray diffraction (PXRD) measurements (Fig. 1a). As shown in Fig. 1a, the samples displayed two weak and broad peaks around at 23 and $44^{\circ}$, which were assigned to the carbon (002) and (100) or (101) plane, respectively. These results indicate that the carbonized MOFs have an amorphous nature. Complete removal of zinc metal was verified by observing the absence of other peaks in PXRD.

Local structure information of carbon was investigated by Raman spectroscopy (Fig. 1b). The pyrolyzed MOFs showed two distinct D and $\mathrm{G}$ bands centered at 1344 and $1587 \mathrm{~cm}^{-1}$ respectively, resulting from the disordered carbon structures and the vibration mode for the movement of two carbon atoms in a single graphene sheet in the opposite direction. The intensity ratio of $\mathrm{G}$ band to $\mathrm{D}$ band $\left(I_{\mathrm{G}} / I_{\mathrm{D}}\right)$ is related to a degree of graphitization in carbon materials. The $I_{\mathrm{G}} / I_{\mathrm{D}}$ values were $0.96,0.87$, and 1.03 for (a)

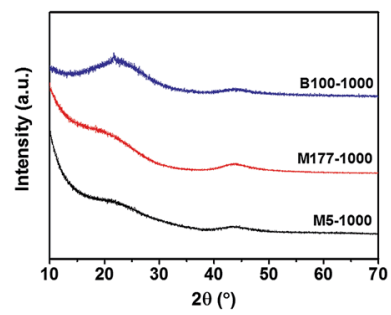

(b)

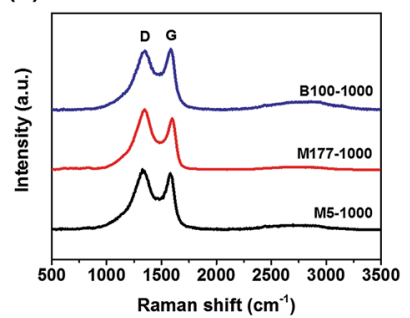

Fig. 1 (a) Powder X-ray diffraction (PXRD) patterns of the porous carbons. (b) Raman spectra of M5-1000, M177-1000, and B100-1000.
M5-1000, M177-1000, and B100-1000, respectively, indicating that the local carbon structures consist of both graphene and disordered carbon. Almost featureless second-order bands (2D and G + D) were observed between 2700 and $3000 \mathrm{~cm}^{-1}$ for all of the samples, suggesting a disordered carbon network as evidenced by the PXRD patterns.

Scanning electron microscopy (SEM) images of the porous carbons are shown in Fig. S3. $\dagger$ Interestingly, each morphology of the parent MOFs was found to be retained, even after heating at high temperature. This indicates that the carbon content of the MOFs is suitable for the formation of carbon materials and the MOF is a stable support for the synthesis of porous carbon materials.

Detailed information about pore structures and surface areas of the pyrolyzed carbon materials was investigated by $\mathrm{N}_{2}$ adsorption-desorption isotherms at $77 \mathrm{~K}$. As shown in Fig. 2a, the isotherms of M5-1000 and M177-1000 revealed type IV shape with noticeable hysteresis, whereas that of B100-1000 exhibited type I shape with insignificant hysteresis. BET surface areas from the $\mathrm{N}_{2}$ isotherms are shown in Table 1. Surface areas of the porous carbons are linearly increased with increasing $\mathrm{Zn}$ contents of parent MOFs precursors (Table 1, Fig. S7 $\dagger$ ). Higher Zn contents in MOF precursors leads to a formation of larger amounts of $\mathrm{Zn}$ nanoparticles in the carbon matrix during the pyrolysis step. Given that an evaporation of these $\mathrm{Zn}$ nanoparticles from the carbon matrix is responsible for the formation of the porous carbon structures, the above linear relationship between $\mathrm{Zn}$ contents and surface area might result from the different ratio of $\mathrm{Zn} / \mathrm{C}$ in the parent MOF. These results are well consistent with the previous work, which was done by Kim and coworkers. ${ }^{19}$ The DFT pore size distributions shown in Fig. S8 $\dagger$ suggest that B100-1000 is micropore-dominant while M5-1000 and M177-1000 have significant amounts of mesopores as well as micropores.

The detailed micropore size analysis was investigated using Horvath-Kawazoe (HK) model (Fig. 2b-d). Interestingly, the

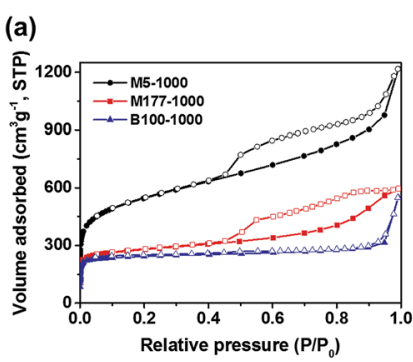

(b)

(c)

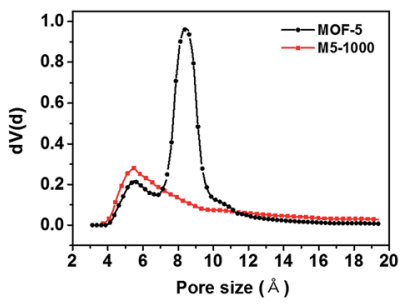

(d)
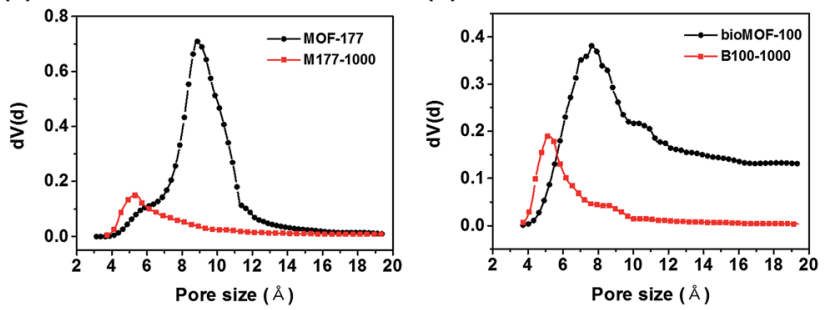

Fig. 2 (a) $\mathrm{N}_{2}$ adsorption-desorption isotherms of the porous carbon materials. (b)-(d) $\mathrm{H}-\mathrm{K}$ pore-size distributions of M5-1000, M177-1000, B100-1000 and their pristine counterparts, respectively. 
Table 1 Summary of $\mathrm{Zn} / \mathrm{C}$ ratio of parent MOFs, BET surface areas, and $\mathrm{CO}_{2}$ uptake properties of the porous carbon materials

\begin{tabular}{|c|c|c|c|c|c|c|c|c|}
\hline & \multirow{3}{*}{\multicolumn{2}{|c|}{$\begin{array}{l}\mathrm{Zn} / \mathrm{C} \text { ratio of } \\
\text { parent MOFs }\end{array}$}} & BET surface area $\left(\mathrm{m}^{2} \mathrm{~g}^{-1}\right)$ & \multicolumn{3}{|c|}{$\mathrm{CO}_{2}$ uptake at $298 \mathrm{~K}\left(\mathrm{mmol} \mathrm{g}^{-1}\right)$} & \multirow[b]{3}{*}{$\begin{array}{l}Q_{\mathrm{st}} \mathrm{CO}_{2} \\
\left(\mathrm{~kJ} \mathrm{~mol}^{-1}\right)\end{array}$} & \multirow[b]{3}{*}{$\begin{array}{l}\text { Selectivity } \\
\text { (IAST) }\end{array}$} \\
\hline & & & & & After pyrc & & & \\
\hline Sample & & & $\begin{array}{l}\text { After } \\
\text { pyrolysis }\end{array}$ & $\begin{array}{l}\text { Parent MOFs } \\
\text { (1 bar) }\end{array}$ & 0.15 bar & $1 \mathrm{bar}$ & & \\
\hline M5-1000 & 0.167 & 3031 & 1978 & 1.09 & 0.81 & 3.13 & $28.1-22.1$ & $21.6-11.0$ \\
\hline M177-1000 & 0.074 & 3337 & 1039 & 1.18 & 0.97 & 3.30 & $27.6-22.9$ & $20.0-13.5$ \\
\hline
\end{tabular}

${ }^{a}$ This value is obtained from ref. 18 .

obtained carbon materials revealed smaller micropore sizes compared to those of parent MOFs. Pore size plays a key role in $\mathrm{CO}_{2}$ capture performance, and narrow pores of $\sim 4 \AA$ to $\sim 8 \AA$ are particularly suitable for $\mathrm{CO}_{2}$ adsorption due to the efficient overlap of attractive potential fields of opposite walls. ${ }^{20}$ Therefore, narrowing pore sizes by pyrolysis of $\mathrm{Zn}$ based MOFs might be a good strategy for $\mathrm{CO}_{2}$ adsorption.

In order to test the above strategy, the $\mathrm{CO}_{2}$ adsorption isotherms of porous carbon materials and their parent MOFs were measured up to 1 bar at 273 and $298 \mathrm{~K}$ (Fig. S9, S10 $†$ and 3a). As expected, all carbon materials revealed superior $\mathrm{CO}_{2}$ capacities compared to those of their parent MOFs (Fig. 3a and Table 1). Recently, Ma and coworkers also reported that porous carbon materials, derived from the carbonization of porous aromatic frameworks (PAFs), showed a remarkable enhancement of $\mathrm{CO}_{2}$ uptake capacity as a result of reduced pore size $(<8 \AA) .{ }^{21}$ In this case, micropore size distributions of the carbon materials were also shrunk to 4-8 $\AA$ after pyrolysis, thus enhanced performances for capturing $\mathrm{CO}_{2}$ are presumably attributed to the generation of confined narrow space. The $\mathrm{CO}_{2}$ uptake for M177-1000 reached $3.30 \mathrm{mmol} \mathrm{g}^{-1}$ at 1 bar and $298 \mathrm{~K}$ which is higher than those of both M5-1000 (3.13 $\mathrm{mmol} \mathrm{g}^{-1}$ ) and B100-1000 (2.69 $\mathrm{mmol} \mathrm{g}^{-1}$ ). Adsorption amounts of all carbon materials were not saturated at $1 \mathrm{bar}$, suggesting a higher adsorption capacity for $\mathrm{CO}_{2}$ at high pressure. Flue gas from the power plants possess $\sim 15 \% \mathrm{CO}_{2}$ at a total pressure of around $1 \mathrm{bar}$; consequently, the $\mathrm{CO}_{2}$ uptake amount at 0.15 bar is an important index to evaluate adsorbents for realistic post-combustion capture of $\mathrm{CO}_{2}$. Uptake amount of M5-1000, M177-1000, and B100-1000 reached 0.81, 0.97, and $0.98 \mathrm{mmol} \mathrm{g}^{-1}$, respectively, at $0.15 \mathrm{bar}$ and $298 \mathrm{~K}$. These values are comparable to those of representative inorganic carbon adsorbents. ${ }^{22}$

Interestingly, the $\mathrm{CO}_{2}$ uptake of $\mathrm{B} 100-1000$ at low pressures was slightly higher than those of M177-1000 and M5-1000 (Fig. S11 and S12†), implying strong interactions between B1001000 and adsorbed $\mathrm{CO}_{2}$ molecules. The isosteric heats of adsorption $\left(Q_{\mathrm{st}}\right)$ of M5-1000, M177-1000 and B100-1000 for $\mathrm{CO}_{2}$ were calculated from the Clausius-Clapeyron equation to determine the adsorption affinity between the porous carbon materials and $\mathrm{CO}_{2}$ molecules. As depicted in Fig. 3b, B100-1000 showed higher $Q_{\mathrm{st}}$ for $\mathrm{CO}_{2}\left(33.9 \mathrm{~kJ} \mathrm{~mol}^{-1}\right)$ at near zero coverage than those of M5-1000 (28.1 kJ mol$\left.{ }^{-1}\right)$ and M177-1000 (27.6 kJ mol$\left.{ }^{-1}\right)$. (a)
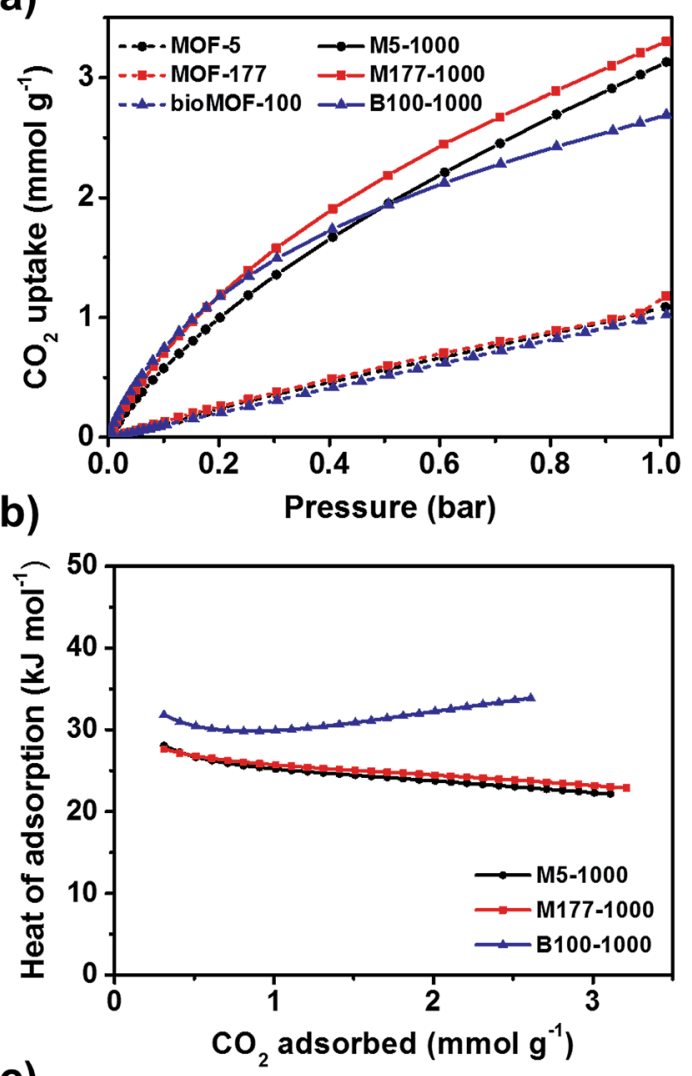

(c)

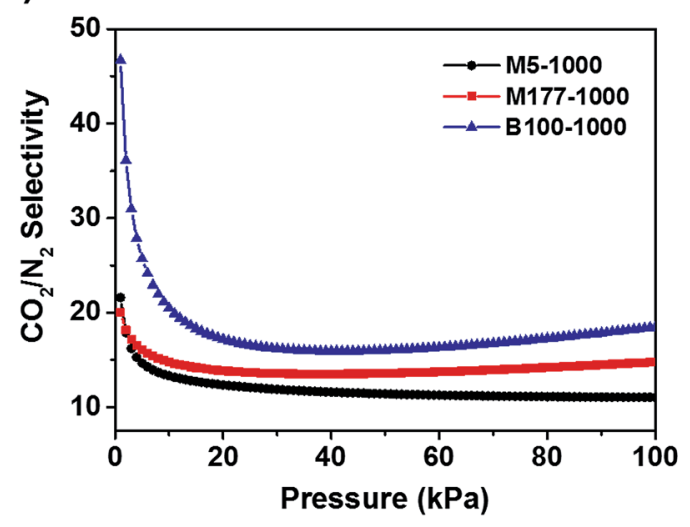

Fig. 3 (a) $\mathrm{CO}_{2}$ adsorption isotherms of the pyrolyzed samples and parent MOFs at $298 \mathrm{~K}$. (b) Isosteric heats of adsorption $\left(Q_{\mathrm{st}}\right)$ of M51000, M177-1000, and B100-1000 for $\mathrm{CO}_{2}$. (c) $\mathrm{CO}_{2} / \mathrm{N}_{2}$ selectivity of M5-1000, M177-1000, and B100-1000 obtained from IAST at $298 \mathrm{~K}$. 
Higher $\mathrm{CO}_{2}$ uptake and $Q_{\mathrm{st}}$ of B100-1000 at low pressures might result from small amounts of Lewis basic nitrogen sites in the carbon matrix which had originated from adeninate ligands in bioMOF-100. X-ray photoelectron spectroscopy (XPS) was carried out to verify the presence of Lewis basic nitrogen in the carbon surface (Fig. S5†). The atomic percentage of $\mathrm{N}$ in B1001000 is $2.69 \%$. The high resolution N 1s spectrum of B100-1000 can be deconvoluted into three peaks corresponding to pyridinic N (398.5 eV), graphitic N (401.3 eV), and N-oxide (403.3 eV) respectively (Fig. S5c $\dagger$ ). The presence of Lewis basic pyridinic $\mathrm{N}$ sites for $\mathrm{CO}_{2}$ adsorption has been emphasized in the previously reported papers. ${ }^{23-25}$ Therefore, the higher affinity of B100-1000 toward $\mathrm{CO}_{2}$ in the low pressure region is attributed to the existence of Lewis basic nitrogen in the porous carbon surface.

Ideal adsorption solution theory (IAST) is normally conducted to predict the adsorptive behaviors of a two-component gas mixture from single-component isotherms. ${ }^{26}$ The IAST adsorption selectivity for $\mathrm{CO}_{2} / \mathrm{N}_{2}$ at $298 \mathrm{~K}$ was calculated for $15 / 85$ gas mixtures. The experimental $\mathrm{CO}_{2}$ and $\mathrm{N}_{2}$ isotherms collected at $298 \mathrm{~K}$ for all carbon materials were fitted to the dual site Langmuir-Freundlich model. Fig. $3 \mathrm{c}$ and Table 1 show the IAST selectivity for $\mathrm{CO}_{2} / \mathrm{N}_{2}$ in the flue gas condition. B100-1000 exhibited better performance for separating $\mathrm{CO}_{2}$ from a gas mixture than other two carbon materials. Selective adsorption of $\mathrm{CO}_{2}$ from $\mathrm{CO}_{2} / \mathrm{CH}_{4}$ gas mixture is an important process in shale gas extraction. Thus, the IAST adsorption selectivity for $\mathrm{CO}_{2} / \mathrm{CH}_{4}$ at $298 \mathrm{~K}$ was also calculated for 50/50 gas mixtures. As depicted in Fig. S14, $\dagger$ M177-1000 showed slightly higher selectivity toward $\mathrm{CO}_{2}$ than other carbon materials. However, selectivity of all porous carbons for $\mathrm{CO}_{2} / \mathrm{CH}_{4}$ are not greatly impressive, this might result from favorable interactions between the hydrophobic carbon surface and methane gas molecules.

Since B100-1000 revealed superior $\mathrm{CO}_{2}$ uptake and separation performance in the flue gas condition, dynamic breakthrough experiments were performed to evaluate the potential of B100-1000 for the adsorptive separation of $\mathrm{CO}_{2} / \mathrm{N}_{2}$ mixtures. Fig. 4 shows the breakthrough curves of $\mathrm{CO}_{2}$ and $\mathrm{N}_{2}$ upon separation of a $\mathrm{CO}_{2} / \mathrm{N}_{2}$ mixture $\left(\mathrm{CO}_{2}: \mathrm{N}_{2}=15: 85\right)$ on a column packed with $\mathrm{B} 100-1000$ pellets. Nitrogen elutes rapidly from the column, whereas carbon dioxide is strongly retained. This clearly shows that B100-1000 can separate $\mathrm{CO}_{2}$ and $\mathrm{N}_{2}$ under dynamic flow conditions. After performing a breakthrough experiment with a $\mathrm{CO}_{2} / \mathrm{N}_{2}$ mixture, the column was regenerated by purging it under a He flow of $40 \mathrm{ml} \mathrm{min}^{-1}$ for $30 \mathrm{~min}$ without heating the column. As shown in Fig. 4, essentially identical breakthrough curves were produced during the three consecutive cycles. This is remarkable because the regeneration was performed under mild conditions. In addition, since flue gases contain considerable amounts of water vapor, it was important to assess the performance of an adsorbent for $\mathrm{CO}_{2} / \mathrm{N}_{2}$ separation under humid conditions $(\mathrm{RH}=50 \%)$. As displayed in Fig. 4b, almost similar breakthrough curves were obtained even in humid conditions. This indicates that this adsorbent retains $\mathrm{CO}_{2} / \mathrm{N}_{2}$ separation ability well under humid conditions. As such, these results demonstrate the separation potential of B100-1000 for $\mathrm{CO}_{2} / \mathrm{N}_{2}$ mixtures under dynamic flow conditions in the presence of water vapor. (a)

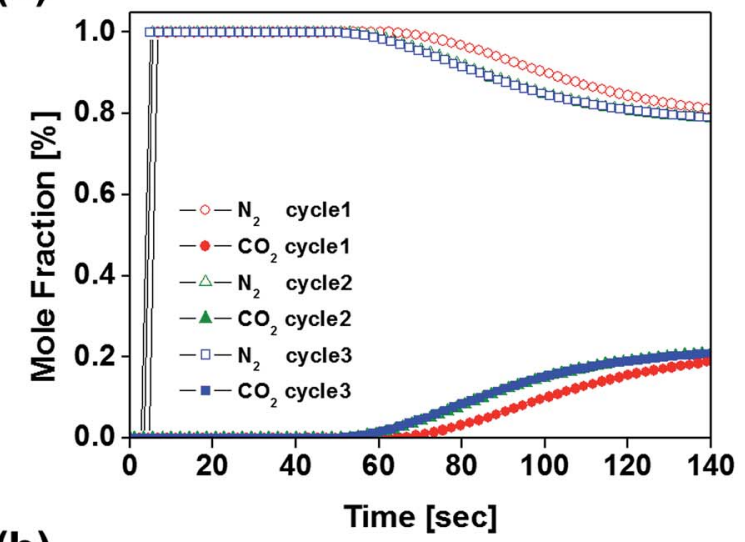

(b)

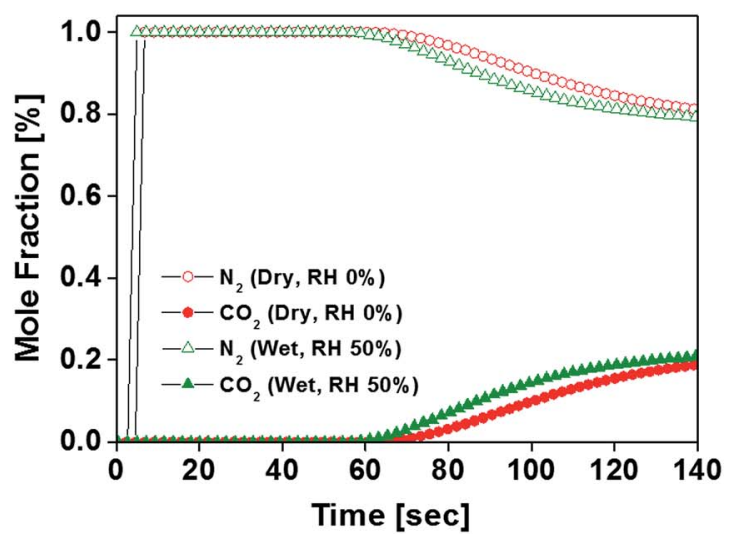

Fig. 4 (a) Experimental breakthrough curves at three consecutive cycles for a packed-bed filled with B100-1000 with a step-input of a dry $\mathrm{CO}_{2} / \mathrm{N}_{2}$ mixture $\left(\mathrm{CO}_{2}: \mathrm{N}_{2}=15: 85\right.$, total flow rate $=40 \mathrm{ml}$ $\mathrm{min}^{-1}$ ) at $303 \mathrm{~K}$ and 1 bar. (b) Breakthrough curves of $\mathrm{CO}_{2} / \mathrm{N}_{2}$ mixture $\left(\mathrm{CO}_{2}: \mathrm{N}_{2}=15: 85\right.$, total flow rate $\left.=40 \mathrm{ml} \mathrm{min}{ }^{-1}\right)$ over $\mathrm{B} 100-1000$ at $303 \mathrm{~K}$ under dry and humid conditions $(\mathrm{RH}=50 \%)$.

\section{Conclusions}

In conclusion, porous carbon materials (M5-1000, M177-1000, and B100-1000) were prepared by simple pyrolysis of pristine MOFs (MOF-5, MOF-177, and bioMOF-100). The pyrolysis step led to the shrunken pore size of these materials and provided a suitable confined-space for $\mathrm{CO}_{2}$ uptake. Consequently, all carbon materials revealed a remarkable enhancement of $\mathrm{CO}_{2}$ uptake capacities compared to their parent MOFs. Among the carbon materials, $\mathrm{N}$-doped porous carbon, B100-1000, exhibited a better adsorption capacity and selectivity for $\mathrm{CO}_{2}$ than other materials in the low pressure region. The existence of the Lewis basic nitrogen is responsible for the improved $\mathrm{CO}_{2}$ uptake. Dynamic breakthrough experiments with B100-1000 showed that B100-1000 can separate $\mathrm{CO}_{2}$ and $\mathrm{N}_{2}$ under dynamic flow conditions. Moreover, the separation ability of B100-1000 was retained even under humid condition during the three consecutive cycles. MOF-derived porous carbons, which have narrow-sized micro-pores and Lewis basic sites, can be an excellent adsorbent for post combustion $\mathrm{CO}_{2}$ capture process. 
We fully expect to see that other zinc and nitrogen-containing MOFs may be suitable precursors for preparing porous carbon adsorbents, and this strategy will be tested in the near future.

\section{Acknowledgements}

This research was supported by the mid-career researcher program through the National Research Foundation of Korea funded by the Ministry of Science, ICT \& Future Planning (NRF2016R1A2B4010376). This work was also supported by the National Research Foundation of Korea under Grant (NRF2016R1A2B4014256). This work was supported by the Seoul National University Research Grant.

\section{Notes and references}

1 E. J. Granite and H. W. Pennline, Ind. Eng. Chem. Res., 2002, 41, 5470-5476.

2 Y. Wang and M. D. LeVan, J. Chem. Eng. Data, 2009, 54, 28392844.

3 M. G. Plaza, S. García, F. Rubiera, J. J. Pis and C. Pevida, Chem. Eng. J., 2010, 163, 41-47.

4 J.-X. Jiang, F. Su, A. Trewin, C. D. Wood, N. L. Campbell, H. Niu, C. Dickinson, A. Y. Ganin, M. J. Rosseinsky, Y. Z. Khimyak and A. I. Cooper, Angew. Chem., Int. Ed., 2007, 46, 8574-8578.

5 X. Xu, C. Song, J. M. Andrésen, B. G. Miller and A. W. Scaroni, Microporous Mesoporous Mater., 2003, 62, 29-45.

6 J. C. Hicks, J. H. Drese, D. J. Fauth, M. L. Gray, G. Qi and C. W. Jones, J. Am. Chem. Soc., 2008, 130, 2902-2903.

7 S. R. Caskey, A. G. Wong-Foy and A. J. Matzger, J. Am. Chem. Soc., 2008, 130, 10870-10871.

8 K. A. Cychosz and A. J. Matzger, Langmuir, 2010, 26, 1719817202.

9 N. Ding, H. Li, X. Feng, Q. Wang, S. Wang, L. Ma, J. Zhou and B. Wang, J. Am. Chem. Soc., 2016, 138, 10100-10103.
10 S.-L. Li and Q. Xu, Energy Environ. Sci., 2013, 6, 1656-1683. 11 G. Srinivas, V. Krungleviciute, Z.-X. Guo and T. Yildirim, Energy Environ. Sci., 2014, 7, 335-342.

12 Q. Wang, W. Xia, W. Guo, L. An, D. Xia and R. Zou, Chem.Asian J., 2013, 8, 1879-1885.

13 H.-L. Jiang, B. Liu, Y.-Q. Lan, K. Kuratani, T. Akita, H. Shioyama, F. Zong and Q. Xu, J. Am. Chem. Soc., 2011, 133, 11854-11857.

14 Y. Shen and J. Bai, Chem. Commun., 2010, 46, 1308-1310.

15 A. Aijaz, N. Fujiwara and Q. Xu, J. Am. Chem. Soc., 2014, 136, 6790-6793.

16 R. Li, X. Ren, X. Feng, X. Li, C. Hu and B. Wang, Chem. Commun., 2014, 50, 6894-6897.

17 H. K. Chae, D. Y. Siberio-Perez, J. Kim, Y. Go, M. Eddaoudi, A. J. Matzger, M. O'Keeffe and O. M. Yaghi, Nature, 2004, 427, 523-527.

18 J. An, O. K. Farha, J. T. Hupp, E. Pohl, J. I. Yeh and N. L. Rosi, Nat. Commun., 2012, 3, 604.

19 S. Lim, K. Suh, Y. Kim, M. Yoon, H. Park, D. N. Dybtsev and K. Kim, Chem. Commun., 2012, 48, 7447-7449.

20 P. Nugent, Y. Belmabkhout, S. D. Burd, A. J. Cairns, R. Luebke, K. Forrest, T. Pham, S. Ma, B. Space, L. Wojtas, M. Eddaoudi and M. J. Zaworotko, Nature, 2013, 495, 80-84. 21 Y. Zhang, B. Li, K. Williams, W.-Y. Gao and S. Ma, Chem. Commun., 2013, 49, 10269-10271.

22 Y. Zhao, X. Liu and Y. Han, RSC Adv., 2015, 5, 30310-30330.

23 W. Xing, C. Liu, Z. Zhou, L. Zhang, J. Zhou, S. Zhuo, Z. Yan, H. Gao, G. Wang and S. Z. Qiao, Energy Environ. Sci., 2012, 5, 7323-7327.

24 L. Li, Y. Wang, X. Gu, Q. Yang and X. Zhao, Chem.-Asian J., 2016, 11, 1913-1920.

25 Y. Chen and J. Jiang, ChemSusChem, 2010, 3, 982-988.

26 A. L. Myers and J. M. Prausnitz, AIChE J., 1965, 11, 121-127. 